\title{
Luzes e blecautes: o público e o privado em Hannah Arendt
}

Recebido em: 12/08/2010

Aceito em: 21/03/2011

\author{
Jorge Roberto Costa Passos ${ }^{1}$ \\ Maria Cláudia Tavares de Mattos ${ }^{2}$ \\ Maria Pontes de Aguiar Campos ${ }^{3}$ \\ Gabryella Garibalde Santana Resende ${ }^{4}$
}

Percorremos, inicialmente, alguns autores clássicos como Platão, Aristóteles, Locke, Marx e outros, na intenção de encontrar uma fundamentação filosófica capaz de iluminar nossa perspectiva. Chegamos a Hannah Arendt, que atendeu plenamente nosso objetivo: compreender o exercício público e privado da saúde em nossa sociedade. Ressalta-se que, embora tenhamos como indiscutível a existência de uma defasagem geral entre os serviços públicos e privados, de modo algum isso é encarado como justo ou natural pela sociedade, seja pela via pública ou privada, mesmo porque tais vias já não são tão rigidamente distintas como eram para a pólis.

Descritores: Saúde, Filosofia, Hannah Arendt, Público e Privado.

\section{Lights and blackout: public and private command post Hannah Arendt}

We first went through some classic authors such as Plato, Aristotle, Locke, Marx and others in the intention to find a satisfactory philosophic reason and really capable of illuminate our perspective. Finally, we got to Hannah Arendt, whom reached completely our objective: to understand the public and private health service that is processing in our society. The conclusion to this process seems to give the public and private sector of equivalent service qualities, what, however, seems far away to accomplish. It is important to notice that, nevertheless we have as indisputable the fact that there is in society a general lag between the public and private service, in any way this is faced as fair or natural for the human being society, which fights for its rights, either by the public or the private way, even because these two ways are not as rigid as they were in thepolis.

Descriptors: Health, Philosophy, Hannah Arendt, Public and Private.

\section{Luz y apagones: el público y privado em Hannah Arendt}

Recurrimos, inicialmente, a algunos autores clásicos como Platón, Aristóteles, Locke, Marx y otros con la intención de encontrar un fundamento filosófico satisfactorio y realmente capaz de iluminar nuestra perspectiva. Finalmente, llegamos a Hannah Arendt, quien atendió plenamente a nuestro objetivo: comprender el ejercicio público y privado de salud que se realiza en nuestra sociedad. La conclusión de este proceso parece dotar el ámbito público y privado de equiparables calidades de servicios que, sin embargo, tal vez estén lejos de realizarse. Además es digno denotar que, a pesar de que tengamos como indiscutible el hecho de que existe un defasaje general entre los servicios públicos y privados, de ninguna manera esto es visto como justo o natural por la sociedad, que exige sus derechos, sea por vía pública o vía privada, hasta porque tales vías ya no son tan rígidamente distintas como eran para la polis.

Descriptores: Salud, Filosofia, Hannah Arendt, Público y Privado.

\section{INTRODUÇÃO}

$\mathrm{P}$ ara entender uma questão ou solucionar um problema, é preciso entender os termos em que a questão ou o problema estão formulados. Sendo assim, as questões e os problemas que envolvem os termos "público" e "privado" parecem não oferecer dificuldade quanto a esse ponto, dado que todos ou a maioria supõe ter suficiente ou até perfeita compreensão de seus significados. Ambos estão presentes em nosso cotidiano, e nada parece mais simples do que usá-los em uma conversa ou informação como algo que é imediatamente evidente sem mais considerações. Diante disso, alguém que se proponha conceituá-los pode ser acusado de falta de senso prático, na pressuposição de que tal conceituação, ainda que exata, nada acrescentaria ao entendimento de uma conversa ou informação contendo tais termos. Mas será mesmo que os termos "público" e "privado" são tão claros assim? Se alguém afirmasse que aquilo que é de uso individual é privado e aquilo que é de uso coletivo é público, certamente receberia instantânea aprovação da maioria. Mas, como deve, quem aprova tal afirmação interpreta a lei $n^{\circ} 9294^{(1)}$, de 15 de julho de 1996 ?

Com a convicção do que acima expusemos, percorremos alguns autores clássicos, como Platão, Aristóteles, Locke, Marx e

1 Filósofo. Mestre em filosofia pela Universidade Federal de Minas Gerais.

2 Enfermeira. Mestre em educação pela Universidade Federal de Sergipe e doutora em ciências médicas pela Universidade de Ribeirão Preto/USP. Docente do Departamento de Enfermagem da Universidade Federal de Sergipe. E-mail: mctm@ufs.br.

3 Enfermeira. Mestre em enfermagem e doutora em saúde da criança e do adolescente - docente do Departamento de Enfermagem da Universidade Federal de Sergipe. 4 Enfermeira. Especialista em processos de ativadores de mudança (Fiocruz). Conselheira e coordenadora da comissão de educação do Coren-SE. 
outros na intenção de encontrar uma fundamentação filosófica capaz de iluminar nossa perspectiva. Finalmente, chegamos a Hannah Arendt, quem, por diversas peculiaridades, atendeu plenamente nosso objetivo. A clareza e consistência de sua exposição, a referência interpretativa dos clássicos, que deu unidade aos resultados de nossa pesquisa, sua abordagem direta e detalhada do ponto que essencialmente nos interessava e, acima de tudo, sua convincente e esclarecedora explicação são as principais peculiaridades que cabem ser aqui mencionadas. $\mathrm{A}$ explanação que segue é nossa apropriação de sua concepção, apropriação essa que, se não for inteiramente fiel a seu espírito, nem por isso deixa de reconhecer que lhe é totalmente devedora.

\section{A ESFERA PRIVADA E A PÚBLICA}

A esfera privada é aquela na qual o ser humano vem ao mundo, ou seja, é imediatamente condicionada por seu aspecto biológico e sua imediata necessidade de obter a sobrevivência, e isso temos em comum com todos os outros animais. Já a esfera pública é especificamente humana: é nela que pode ser desenvolvida a práxis ou ação, isto é, aquilo que distingue o homem de todos os outros seres que conhecemos $^{(2)}$. As demais atividades próprias do ambiente privado ou familiar não podem adequadamente receber a mesma designação. Portanto, fica desde logo estabelecido que, com o devido rigor, não podemos usar indiferentemente os termos "ação (práxis)" e "atividade" como simples sinônimos.

A esfera pública, por seu lado, éestabelecida quando muitas famílias se reúnem e formam o Estado. Não importa se o que levou tais famílias a se reunirem foi também causado pela necessidade de garantir a sobrevivência. Importa sim que, ao criar o Estado, surgiu um espaço de relacionamento onde o ser humano experimentou pela primeira vez uma espécie de atividade caracterizada não mais pela necessidade da simples sobrevivência. O comando e a necessidade imediata de obedecer são substituídos pelo debate e pelo livre estabelecimento de regras comuns ${ }^{(2)}$.

Portanto, assim como a necessidade domina o meio privado e familiar, a liberdade domina o meio público. Os antigos gregos atribuíram ao conhecimento das coisas privadas o termo "economia" e ao conhecimento das coisas públicas o termo "política". Aquilo que os homens fazem no espaço público ou político é o que decorre de sua liberdade e, em virtude disso, tais realizações estão sujeitas à adjetivação de "grandiosas" e são chamadas por "feitos".

Essa realidade acima descrita, existente na antiga pólis grega, não nos é estranha; temos suficientes conceitos para compreendê-la. Contudo, vemos facilmente que não corresponde inteiramente à nossa realidade. Mas é notável, naquilo que concerne o objeto de nosso presente tema, que os gregos da pólis tinham, de fato, uma perfeita noção da distinção entre público e privado, a qual nós supomos muitas vezes que também tínhamos, mas que, de fato, não temos ${ }^{(2)}$. Nossa noção imediata e de senso comum é muito próxima ou até semelhante no essencial àquela dos gregos, mas nossa realidade, que deveria ser iluminada por tais conceitos, é bem distinta. Pagamos pelofato dearealidade sealterarmais rapidamente que os conceitos e também pelo fato de necessitarmos de conceitos que representem uma realidade derivada e mais complexa e onde os âmbitos "público" e "privado" não estão mais tão rigidamente separados como estavam na pólis.

Conforme Arendt( ${ }^{(3: 33)}$, no pensamento grego, "a capacidade humana política não apenas difere, mas é diretamente oposta a essa associação natural cujo centro é constituído pela casa (oikia) e pela família. $O$ surgimento da cidade-estado significava que o homem recebera, 'além da vida privada, uma espécie de segunda vida, seu bios politikos. Agora cada cidadão pertence a duas ordens de existência; e há uma grande diferença na vida entre aquilo que Ihe é próprio (idion) e o que é comum (koinon)' (Jaeger). De todas as atividades necessárias e presentes nas comunidades humanas, só duas eram consideradas políticas e constituintes do que Aristóteles chamava de bios politikos: a ação (praxis) e o discurso (lexis), dos quais surge a esfera dos negócios humanos (ta ton) anthropon pragmata, como chamava Platão, que exclui estritamente tudo que seja apenas necessário ou útil".

$\mathrm{Na}$ antiga cidade-estado, as esferas pública (com a política) e privada (com a economia) jamais se confundem ou misturam e cada uma atende a um aspecto da vida humana. A mentalidade antiga entendeu que esses aspectos deveriam manter-se separados um do outro por uma rígida demarcação. A ascendência da esfera social, como um terceiro elemento relevante na organização da vida civilizada humana, é um fenômeno historicamente novo, que surge na era moderna com o advento do Estado nacional(2).

Torna-se difícil para nós compreender a divisão rígida entre as esferas pública e privada e entre as atividades pertinentes a um mundo comum e as pertinentes à manutenção da vida, divisão essa na qual se baseava todo o antigo pensamento político, que a encarava com naturalidade e como evidente por si mesma. Para nós, atualmente, tal linha divisória não existe, pelo menos não do modo simples, claro e rígido como era para os antigos.

\section{DA PÓLIS GREGA ATÉ NÓS, UM LONGO CAMINHO HISTÓRICOÉ PERCORRIDO}

Hoje, um terceiro elemento além do doméstico e do político, já existente entre os gregos, tanto quanto em qualquer civilização - o elemento social -, assumiu vastas dimensões. Até antes de Locke e do advento da sociedade moderna, era comum e até regra não considerar o aspecto social ou até mesmo confundi-lo com o político. Pode-se considerar Hobbes (1588-1679), que antecedeu imediatamente Locke (1632-1704) como o último teórico político de relevância a identificar o social com o político.

Na concepção hobbesiana do estado de natureza, isto é, a 
condição hipotética em que viveriam os homens sem a existência do Estado, a sociedade era considerada inexistente; e o Estado seria uma invenção artificial concebida pela razão, motivada pelo medo e pelo esforço de preservação dos homens que viviam isolados, no máximo associados aos membros de sua família. A própria expressão "sociedade civil"é usada por Hobbes em sentido totalmente diverso do atual como sendo ela meramente sinônima de "Estado", tal como também era tomado o termo"cidade" (2).

"[...] aquele que se submete à vontade de outrem transfere a esse último o direito sobre sua força e suas faculdades - de tal modo que, quando todos os outros tiverem feito o mesmo, aquele a quem se submeteram terá tanto poder que, pelo terror que esse suscita, poderá conformar as vontades dos particulares à unidade e à concórdia. A união assim feita diz-se uma cidade, ou ainda uma pessoa civil, pois, quando de todos os homens há uma só vontade, essa deve ser considerada como uma pessoa, e pela palavra uma deve ser conhecida e distinguir-se de todos os particulares.."(4)

Locke, em consonância com as transformações históricas que presenciou, concebeu que, mesmo antes do estabelecimento do Estado, os homens já viviam em sociedade, mas tiveram de inventar o Estado e a lei positiva para garantir a justiça e a preservação do direito natural e da propriedade. Em sua perspectiva, a propriedade não mais é concebida como convencional e dependente do arbítrio do poder soberano estatal - (como julgava Hobbes) e, consequentemente, como uma instituição inteligível apenas como sendo posterior ao estabelecimento do Estado ${ }^{(5)}$.

Nesse embate teórico entre Hobbes e Locke, pode-se dar parcial razão a ambos. Locke, por seu lado, não confunde o social com o político como faz Hobbes, mas, ao tomar a realidade histórica que the era contemporânea como absoluta e válida para qualquer época, inviabilizou, em sua teoria, a compreensão do pensamento político antigo e do próprio desenvolvimento histórico da realidade. Hobbes não deixou de considerar sua teoria como absoluta e válida para qualquer época. Mas, sob a influência de Tucídides, formulou uma concepção em harmonia com a ordem dos fatos. E, embora desconsiderando grande parte das transformações que em seu tempo começavam a se processar (devido à sua pressuposição errônea que identifica social com político), não cometeu o erro de Locke, que admitia que ao estabelecimento da esfera pública preexistisse um complexo sistema social tal como estava se firmando em sua época e que hoje faz parte essencial de nossa vida( ${ }^{(3)}$.

O abismo entre privado e público ainda existia de certa forma na Idade Média, embora houvesse perdido muito de sua importância e mudado inteiramente de localização. Após a queda do Império Romano, foi a Igreja Católica que ofereceu ao homem um substituto para a cidadania antes outorgada exclusivamente pelo governo municipal. A tensão medieval entre a treva da vida diária e o grandioso esplendor de tudo que era sagrado corresponde em muitos aspectos à ascensão do privado ao plano público ${ }^{(6)}$. $\mathrm{O}$ que mantinha coesa a comunidade de crentes era essencialmente uma preocupação extraterrena. É típico dessa evolução da esfera privada - e da diferença entre o antigo chefe da família e o senhor feudal que esse último pudesse administrar justiça dentro dos limites de seu domínio, ao passo que o antigo chefe de família, embora pudesse exercer um domínio mais ameno ou mais severo, não conhecia leis nem justiça fora da esfera pública. Ocorre uma transferência de todas as atividades humanas para a esfera privada e o ajustamento de todas as relações humanas segundo o molde familiar.

O que distingue da realidade moderna, essa atitude essencialmente cristã em relaçãoà políticaéa exclusividade da esfera privada e a ausência daquela esfera híbrida que chamamos hoje de "sociedade", na qual os interesses privados assumem importância pública. Portanto, no processo evolutivo desde os gregos até nós, os medievais pareciam preparar o terreno para que os assuntos privados pudessem futuramente ganhar relevância pública, à medida que, ao aniquilar o espaço público tal como existia entre os antigos, estabeleceu uma expansão das preocupações privadas sobre as atividades humanas.

Hoje, não apenas não concordaríamos com os gregos que uma vida vivida na privatividade do que próprio ao indivíduo (idion), à parte do mundo comum, é "idiota" por definição, mas tampouco concordaríamos com os romanos, para os quais a privatividade oferecia um refúgio apenas temporário contra os negócios da res publica $^{(3)}$. O que hoje chamamos de privado é um círculo de intimidade, cujos primórdios podemos encontrar nos últimos períodos da civilização romana, embora dificilmente em qualquer período da antiguidade grega.

Hoje, pouco importa se uma nação se compõe de homens iguais ou desiguais, pois

a sociedade exige sempre que seus membros ajam como se fossem membros de uma enorme família dotada apenas de uma opinião e de um único interesse. Antes da moderna desintegração da família, esse interesse comum e essa opinião única eram representados pelo chefe da família, que comandava segundo opinião e interesse e evitava uma possível desunião entre os membros de sua casa.

A coincidência da ascensão da sociedade com o declínio da família indica claramente que ocorreu, na verdade, a absorção da família por grupos sociais correspondentes. A igualdade dos membros desses grupos, longe de ser uma igualdade entre pares, lembra muito mais a igualdade dos membros da família ante o poder despótico do chefe da casa - exceto que, na sociedade, onde a força natural de um único interesse comum e de uma opinião unânime é tremendamente intensificada pelo próprio peso dos números, o poder exercido por um único homem, representando o interesse comum e a opinião adequada, podia mais cedo ou mais tarde ser dispensado. O fenômeno do conformismo é característico do último estágio dessa evolução moderna. Nessa situação, ocorre uma espécie de governo de ninguém. Mas esse ninguém, o suposto interesse único da sociedade como um todo em questões econômicas, não deixa de governar por ter perdido a personalidade. 
Egoverno de ninguém não é o mesmo que ausência de governo: de fato, em certas circunstâncias, pode até vir a ser uma das mais cruéis e tirânicas versões de governo.

A sociedade é a forma na qual o fato da dependência mútua em prol da subsistência, e de nada mais, adquire importância pública e na qual as atividades que dizem respeito à mera sobrevivência são admitidas em praça pública. Seu princípio já não é mais a ação e sim o comportamento; a avaliação do que se faz na esfera pública depende desse novo critério, ou seja, do comportamento que se espera e não mais da distinção na ação individual. Isso evidencia que ocorreu uma enorme transposição da realidade privada para o domínio público e, em sentido inverso, o homem passou a compreender o ambiente privado como espaço de ações e realizações, o que antes os antigos julgavam exclusivo da esfera pública.

\section{CONSIDERAÇÕES FINAIS}

Dentro de todo esse quadro geral que engloba a vida humana civilizadaenosfazcompreenderseuprocesso evolutivo desde os antigos gregos até nós, revelando como da prévia organização da existência humana nas simples e bem demarcadas esferas econômica (restrita ao privado) e política (restrita ao público) chegamos a uma complexa organização da existência humana, onde o social dinamiza interferências políticas no privado e eleva atividades econômicas ao domínio público, que tipo de recorte podemos fazer para compreender o exercício público e o exercício privado da saúde que se processa em nossa sociedade? Notemos que a própria pergunta, embora pertinente e necessária nessa altura, não faria sentido para alguém que vivia sob a mentalidade antiga, pois inclui o termo "sociedade" no sentido de sociedade civil.

De acordo com o que foi visto anteriormente, sendo a saúde parte das necessidades relativas à sobrevivência, é óbvio que os gregos a relegavam totalmente à esfera privada. Mas de modo algum foi essa determinação estabelecida pela sociedade, pois essa, tal como é hoje concebida, era inexistente ou irrelevante na antiga pólis. Antes, os próprios indivíduos, agindo naturalmente de acordo com sua mentalidade própria, sequer pensavam em atribuir à política responsabilidades referentes à saúde de cada um. Mesmo que alguns preceitos relativos à preservação, obtenção ou recuperação da saúde pudessem ser codificados e mencionados em leis, nenhum deles jamais conduziu as coisas até o ponto de atribuir ao Estado ou à esfera pública qualquer obrigação de criar e administrar serviços públicos de saúde.

Entre os medievais, o aspecto social (a propensão à associação) ganha força e, pela primeira vez, começa a se flexionar a rígida linha divisória que separa o econômico do político. A lgreja começa, com sua vocação assistencial, a estabelecer um germe do serviço público de saúde. Ainda é ausente aquela consequência da expansão do elemento social a que chamamos "sociedade civil", pois essa só é viável a partir do Estado nacional. Mas pela primeira vez a organização da vida humana experimenta interseções entre as esferas pública e privada, ainda que de forma bastante incipiente.

É com a modernidade que a saúde, de fato, deixa de ser uma peculiaridade exclusiva da vida econômica privada e ganha uma nova forma de expressão na vida política pública e na nova esfera econômica pública. Os grandes avanços da medicina, associados ao progresso das ciências biológicas, que ocorrem nesse momento histórico, estão certamente ligados à socialização da busca pela preservação, obtenção e recuperação da saúde. A partir de então, a saúde não é mais apenas uma parte dos interesses econômicos restritos à esfera privada; ela ganha relevância política e pública e, enquanto econômica, assume também um papel público. É dentro desse contexto que o médico passa a ser encarado como capaz de altos feitos e realizações e sua atividade passa a ser encarada como ação (praxis), isto é, atividade especificamente humana ${ }^{(6: 141)}$.

Finalmente, com a extrapolação do aspecto social além dos limites do Estado nacional, assistimos hoje à consolidação em andamento da sociedade humana ou sociedade da espécie humana (societas generis humani). Essa nova forma de sociedade, com seu poder de interferência cada vez mais alto, estabelece exigências sobre as esferas pública e privada, as quais, como já sabemos, possuem atualmente inúmeros espaços de interseção. Próprio dessa fase é o surgimento de instituições e organizações como a Organização Mundial da Saúde (OMS) e outras, com atribuições que ultrapassam os limites nacionais. A conclusão desse processo parece ser a de dotar o âmbito público e o privado de equiparáveis qualidades de serviços, o que, entretanto, talvez esteja longe de se realizar. E é digno de nota que, embora tenhamos como indiscutível o fato de que existe uma defasagem geral entre os serviços públicos e privados, de modo algum isso é encarado como justo ou natural pela sociedade da espécie humana, a qual reivindica seus direitos, seja pela via pública, seja pela via privada, mesmo porque tais vias já não são tão rigidamente distintas como eram para a pólis.

\section{Referências}

1. Senado Federal (BR). Lei 9294/96. Dispõe sobre as restriçōes ao uso eà

propaganda de produtos fumígeros, bebidas alcoólicas, medicamentos, terapias e defensivos agrícolas, nos termos do $\S 4^{\circ}$ do art. 220 da Constituição Federal. Brasilia: Diário Oficial da República Federativa do Brasil; 1996. 16 dez; Seção 1, p. 13074 2. Fabre SG. Os princípios filosóficos do direito político moderno. São Paulo: Martins Fontes; 1999.

3. Arendt H. A condição humana. 10ª ed. Rio de Janeiro: Forense Universitária; 2007. 4. Hobbes T. Do cidadão. São Paulo: Martins Fontes; 1992.

5. Locke J. Dois tratados sobre o governo. 2ª ed. São Paulo: Martins Fontes; 2005. 6. Heimann $L S$, Ibanhes $L C$, Barboza R, organizadores. O público e o privado na Saúde. São Paulo: Hucitec; 2005. 